\title{
TRANSFORMACIONES TERRITORIALES DE LAS ÁREAS COSTERAS: ANÁLISIS DE LA COSTA MALAGUEÑA EN LA SEGUNDA MITAD DEL SIGLO XX
}

\author{
Ricardo Manuel Luque Revuelto \\ Universidad de Córdoba \\ ch1lurer@uco.es \\ ORCID iD: http://orcid.org/0000-0001-6148-4043
}

Recibido: 20/10/2019; Aceptado: 15/12/2020; Publicado: 17/06/2021

Cómo citar este artículo/citation: Luque Revuelto, Ricardo Manuel (2021). Transformaciones territoriales de las áreas costeras: análisis de la Costa Malagueña en la segunda mitad del siglo XX. Estudios Geográficos, 82 (290), e062. https://doi.org/10.3989/ estgeogr.202074.074

\begin{abstract}
Resumen: El estudio de la Costa Malagueña es imprescindible para entender las profundas transformaciones territoriales que ha sufrido las áreas costeras españolas en la segunda mitad del siglo XX. Los libros de Derrotero son un instrumento imprescindible para la navegación litoral, pero a la vez constituyen un testigo extraordinario de estas transformaciones recientes. El Derrotero aporta una nueva perspectiva al estudio de dichas áreas, pues supone un punto de vista diferente al satelital o a la imagen cartográfica, una nueva perspectiva dada por la visión horizontal de la línea de costa que dibujan. Se exponen las características y la evolución de los Derroteros que comprenden la Costa Malagueña y se plantea como objetivo fundamental el de determinar, desde un punto de vista geográfico, su validez para el estudio de los espacios costeros y su evolución.
\end{abstract}

Palabras clave: Áreas costeras, libros de Derrotero, náutica, turismo de sol y playa, Costa del Sol (Málaga).

\section{TERRITORIAL TRANSFORMATIONS OF COASTAL AREAS: ANALYSIS OF THE MALAGUEÑA COAST IN THE SECOND HALF OF THE 20TH CENTURY}

Abstract: The study of the Costa Malagueña is essential to understand the profound territorial transformations that the Spanish coastal areas have suffered in the second half of the 20th century. The Derrotero books are an essential instrument for the coastal navigation, but simultaneously they constitute an extraordinary witness to these recent transformations. The Derrotero provides a new perspective to the study of these areas, since they suppose a point of view different from the satelital or from the cartographic image satellite, a new perspective given by the horizontal vision of the coastline that they draw. The characteristics and evolution of the Derroteros that comprise the Costa Malagueña are exposed and the fundamental objective is to determine, from a geographical point of view, their validity for the study of coastal spaces and their evolution.

Key words: Coastal areas, Derrotero books, nautical, sun and beach tourism, Costa del Sol (Málaga). 


\section{INTRODUCCIÓN}

La pérdida o la modificación de las referencias geográficas, de la misma manera que se pierden las referencias culturales o la biodiversidad del planeta, parece ser la constante actual de una sociedad urbana cada vez más globalizada (Castells, 1989). Síntomas de ello son la postergación de la cartografía tradicional o su escasa consideración en los currículos de geografía (AGE, 2014). Otro indicio de ello es la aparición de nuevos y rápidos sistemas de transporte y posicionamiento que no consideran el trayecto, ni los espacios que transitan, sino tan solo el lugar de partida y el de llegada. Es así como se puede prescindir del conocimiento del territorio, de los puntos destacados del relieve, de los ríos o valles que el viajero va atravesando -incluso de los pueblos y localidades, en unas vías rápidas de transporte-. De esta forma, el espacio geográfico parece difuminarse para buena parte de la ciudadanía, que solo reconoce su localidad de residencia y otros destinos, restando entre ellos grandes espacios vacíos de conocimiento espacial. Paradójicamente, esta situación descrita parece no estar reñida con la popularización y la proliferación de abundante información de carácter espacial, impulsada por las nuevas tecnologías, que aplicadas al mundo de la geografía han supuesto en la actualidad, la divulgación masiva de imágenes espaciales y el desarrollo de nuevas técnicas de análisis y de conocimiento (Álvarez y Lázaro, 2019; De Miguel, 2018; Luque, 2011).

En cambio, parece no existir la misma percepción en el conocimiento de los espacios litorales observados o transitados desde el medio marino. La necesidad de obtener una localización constante, con el objetivo de mantener un rumbo determinado, obliga a los navegantes a identificar todas las referencias geográficas del continuo que es la línea de costa, como, por ejemplo, los puntos más prominentes de los relieves continentales, que fueron referentes para la navegación a vela y continúan siendo referentes de primer orden para la navegación actual. En cambio, esos mismos puntos, que también fueron hitos para los viajeros por tierra, para comerciantes o arrieros que hacían sus rutas por el interior ya han dejado de serlo.

También es cierto que la navegación moderna cuenta con avanzados sistemas de localización y rumbo que permiten pilotar a ciegas, sin embargo, continúa siendo de cumplimiento obligado disponer a bordo, en el cuarto de derrota, con las fuentes de información tradicional impresas: las cartas náuticas, los libros de derrotero y faros, los anuarios de mareas, etc., imprescindibles si los medios técnicos fallan. Por tanto, se podría afirmar que, en las actividades náuticas, en general, y de forma particular, en los libros de Derrotero, se conservan y tiene plena vigencia -aunque con bastantes modificaciones como trataremos de mostrar en este texto- las referencias, accidentes o hitos geográficos tradicionales y que son visibles en el litoral. Es más, en otras épocas los principales avances en el conocimiento geográfico se produjeron gracias a la observación directa de las expediciones marítimas que llevaron a cabo geógrafos de diferentes épocas, desde Idrisi hasta von Humboldt o Russel Wallace. Convenimos con Suárez (1979) que el espacio marítimo sigue siendo objeto de estudio de la geografía, si bien a fecha de hoy continúa teniendo un tratamiento escasamente cohesionado, lo que no resta interés ni significación a las investigaciones geográficas como ponen de manifiesto los textos de Nonn (1987), Miossec (1998) o los trabajos de la Comisión de la Mer del Comité National Français de Géographie (Durand, 2005).

Los objetivos de este trabajo son los de exponer las características de los libros de Derrotero, analizar los relativos a la Costa Malagueña y, finalmente, determinar su validez desde un punto de vista geográfico para el conocimiento de los espacios costeros, sus modificaciones y su evolución en la segunda mitad el siglo XX. Los derroteros muestran las marcas en el territorio y por eso son una herramienta para el análisis geográfico. Ahora bien, aunque dichas marcas permiten constatar la realidad que uno observa, resulta imprescindible el concurso de otras fuentes y trabajos de campo para hipotetizar, refutar o verificar las transformaciones de un territorio. Se trata de demostrar que la trascendencia que tuvieron en el pasado sigue vigente en el presente, y aunque ya no resulten cruciales por los nuevos avances técnicos, siguen constituyendo un punto de vista complementario y necesario, no solo para la navegación, sino para una mejor comprensión de los espacios costeros. De manera que, si se comparan diferentes ediciones del Derrotero, se pueden apreciar importantes modificaciones en las referencias geográficas utilizadas que, a su vez, nos permiten conocer los cambios producidos en unos espacios sometidos a un fuerte dinamismo físico, biológico y humano.

Estos cambios se ejemplifican de forma singular en la Costa Malagueña, por tratarse de una de las que mayores transformaciones ha experimentado de todas las áreas costeras mediterráneas a lo largo de la segunda mitad del siglo XX, un espacio clave para la comprensión del fenómeno del turismo de masas, de la litoralización de la población y el poblamiento, o de la terciarización de la economía. Pero se trata también de un espacio en donde se han generado conflictos de toda índole, desde el medioambiental y el paisajístico, hasta las tensiones generadas por la competencia por el agua y el suelo entre la agricultura litoral y otras actividades, o la privatización de los dominios públicos litorales. Estos fenómenos han sido caracterizados, para el periodo estudiado, por autores como: Ferre y 
Ruiz (1986), Marchena (1987 y 1988), Galacho (1996 y 2000), García (2000) o Vallejo (2002). En el presente, los anteriores procesos y conflictos mencionados, aunque no resueltos, han ido evolucionando de forma desigual como demuestra la bibliografía más reciente en lo referente a los recursos naturales o el medio ambiente (Gallegos, 2018; Río, 2017), el planeamiento urbanístico (Górgolas, 2020), la dinámica demográfica (González y Blay, 2019; Natera y Batista, 2019) o la actividad turística (Almeida, 2019; Navarro, Romero y Romero, 2020; Simancas, 2016).

Pero también, resulta cada vez más imprescindible en el estudio de los espacios costeros el empleo de los Sistemas de Información Geográfica (SIG), que se nutren de una renovada cartografía y fotografía aérea o a vista de satélite. Son fuentes de información y análisis que se incorporan a buena parte de la bibliografía más reciente, como en un estudio del Instituto de Estadística y Cartografía de Andalucía (IECA, 2016) que se fundamenta en la comparación de ortofotografías e imágenes satelitales del litoral malagueño. Así, a las series del MTN del Instituto Geográfico Nacional se han incorporado escalas de mayor detalle y formatos digitales. A los mosaicos convencionales de ortofotografías e imágenes satelitales como las del Landsat se añaden, por ejemplo, la ortofoto PNOA del Plan Nacional de Ortofotografía Aérea o los mosaicos nacionales Sentinel 2 del programa europeo Copernicus, que cuentan con un periodo de actualización semestral. La cartografía temática también se ha ampliado, destacando, entre otros, los mapas del CORINE Land Cover, el Mapa fisiográfico del litoral de Andalucía, o el Mapa de Morfología de los fondos marinos del litoral de Málaga, Granada y Almería. Todos ellos disponibles en los servidores Web Map (WMS) del Centro Nacional de Información Geográfica (CNIG) o del Instituto de Estadística y Cartografía de Andalucía (IECA).

\section{METODOLOGÍA}

Desde un punto de vista metodológico se ha efectuado un análisis de tipo cualitativo, fundamentado en el estudio de las fuentes bibliográficas y documentales que se citan. Como fuente primaria de información e instrumento de análisis se llevó a cabo un extenso trabajo de campo, tanto en el medio terrestre como en el medio marino. En la costa se dispuso de embarcaciones de diferente eslora, tanto a vela como a motor, navegando en el sentido oeste-este que describe el Derrotero y a distancias variables, cabotaje que resultó imprescindible para verificar las observaciones descritas y validar los cambios producidos ya existentes y que concurren a nivel local. Igualmente se procura no perder de vista las nociones de escala, lugar, paisaje, territorio y región (Dollfus, 1975) que permiten diferenciar y aquilatar los hechos geográficos considerados en cada etapa.
A partir de dichas realidades se plantean, de forma abierta y flexible, las observaciones y diferentes explicaciones que puedan dar respuesta a la hipótesis inicial que trata de validar la importancia que tienen los libros de Derrotero desde un punto de vista geográfico para el conocimiento de la costa de Málaga y su evolución. La importancia del Derrotero como fuente de información geográfica y sus aportaciones en el análisis del territorio costero quedan de manifiesto cuando se advierte, en dichos libros, elementos del territorio que no aparecen, o no son suficientemente visibles en la cartografía convencional, o no se relacionan en las fuentes bibliográficas o documentales consultadas. Aportan una nueva perspectiva, dada por la visión horizontal de la línea de costa que dibujan y no duplican la información geográfica, pues vienen o corroborar o a matizar las otras fuentes, siendo todas ellas complementarias entre sí. Pero, en efecto, el Derrotero también presenta deficiencias, cuando se considera como fuente de información geográfica, por su finalidad, por su propia condición de publicación náutica, o por su complejidad.

En los apartados sucesivos se detallan, en primer lugar, las características y contenidos de las publicaciones náuticas, seguidamente se identifican las modificaciones de las referencias geográficas en dos etapas: la comprendida entre 1950 y 1974, y la que abarca entre esta fecha y finales del siglo XX. Fechas que coinciden, respectivamente, con: el inicio de la expansión y consolidación del turismo en la Costa del Sol, con una modificación y reajuste del turismo litoral como consecuencia de la crisis del petróleo de 1974, y finalmente con una etapa caracterizada por la aparición de nuevos modelos turísticos y renovadas políticas tanto de la administración central como autonómica. Para su análisis contamos con la publicación del Derrotero en tres fechas clave: la de 1950, la de 1973 y la de 1998 (Instituto Hidrográfico de la Marina, 1950, 1973 y 1998).

Se impone, por tanto, un punto de vista diacrónico y a la vez sincrónico de estas etapas y sus hitos, enfoques diferentes a la vez que complementarios. Así se inicia el análisis en un momento de partida que coincide con el año, 1950, hasta llegar a otra fecha ya a finales de siglo, siendo los años de 1973-1974 los que marquen la separación entre dos períodos bien diferenciados.

\section{LOS LIBROS DE DERROTERO}

Los libros de Derrotero son una publicación del Instituto Hidrográfico de la Marina que describen detalladamente las costas españolas. Tienen la finalidad de servir de guía a los navegantes que se aproximan al litoral y las indicaciones contenidas en ellos permiten ubicar la posición de los navíos sobre una carta náuti- 
ca. En otras épocas constituían la única referencia para la navegación costera, si bien, actualmente, parte de la información que aportan se puede obtener mediante los sistemas de posicionamiento por satélite.

El diccionario de la RAE define Derrotero en una de sus acepciones como: "Conjunto de datos que indican el camino para llegar a un lugar determinado" y en otra como: "Línea señalada en la carta de marear para el gobierno de los pilotos en los viajes", siendo esta última, sinónimo de rumbo.

El Derrotero es una publicación seriada con una periodicidad, que no es fija, pero que suele ser inferior a los diez años desde mediados del pasado siglo. La misma proliferación de ediciones, en donde la última anula a las anteriores, además de ser un claro exponente de la celeridad con la que se ha venido produciendo la alteración del litoral, es un hecho que permite conocer los cambios y la diferente intensidad con la que se han producido estos.

El Derrotero completa la información de las cartas náuticas. En las cartas se señalan las coordenadas geográficas y se dibuja la línea de la costa, las curvas isobáticas, los faros y señales de balizamiento o los puntos de recalada, entre otras. En el Derrotero se expone una detallada y precisa información geográfica, que queda de manifiesto en la exactitud en las localizaciones, de los rumbos o derrotas, enfilaciones, oposiciones y distancias de los elementos que comprenden las cartas náuticas.

Son libros que además muestran una fina sensibilidad geográfica, la cual queda de manifiesto en la percepción de esa estrecha relación que existe entre el mar y el continente en la banda costera, superando la prevalencia que el uso cotidiano ha asignado a término costa como parte del medio terrestre frente a litoral en relación con el medio marino (Suárez, 1999). Y lo hacen desde un enfoque sistémico, en donde se interrelacionan los diferentes elementos y factores que confluyen en ella, no de una forma yuxtapuesta, sino concatenada. Así, se pone de manifiesto en las detalladas descripciones que muestran la estrecha concordancia que existe entre los fondos marinos, los espacios intermareales o los relieves litorales con el clima, los vientos o las corrientes marinas.

FIGURA 1

MAPA INDICE DEL DERROTERO DE LAS COSTAS DEL MEDITERRÁNEO

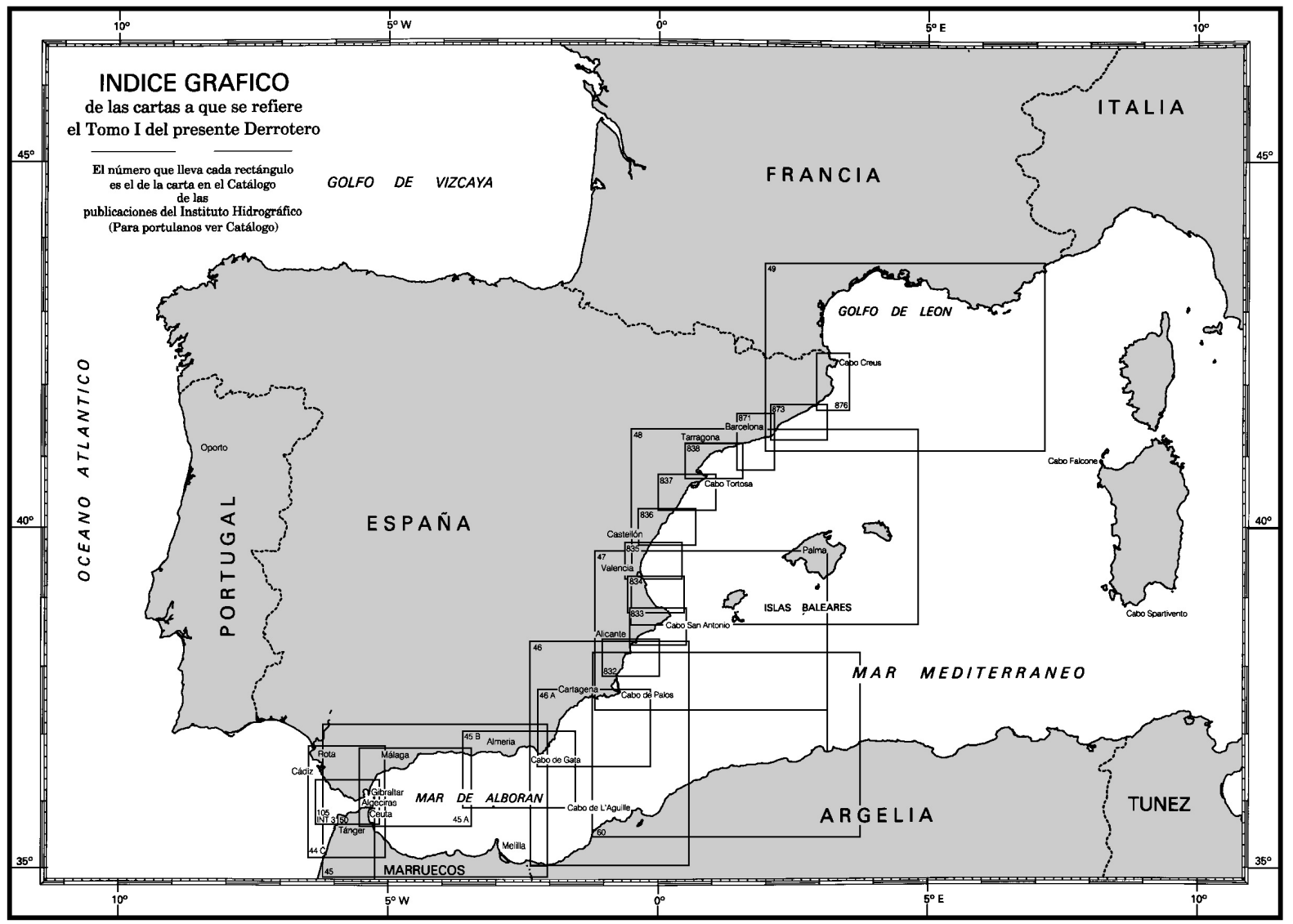

Fuente: Derrotero de las Costas del Mediterráneo Núm. 3, Tomo I. Servicio de Publicaciones de la Armada. Cádiz, 1998, p. 14. 
Ha sido la experiencia náutica de siglos de navegación y las notas aportadas por los marinos, que navegaron en condiciones mucho más duras que las actuales, las que ha ido recogiendo el Instituto Hidrográfico de la Marina desde su creación en 1944, pero que ya llevaron a cabo la Casa de Contratación que fundasen los Reyes Católicos en 1503 o el archivo de Indias creado en 1785 por Carlos III.

Los antecedentes del Derrotero actual más destacados han sido: El Atlas de las Costas de España de Pedro Teixeira (1634), el Derrotero de Vicente Tofiñó (1787) o el de Pedro Riudavets (1867). Estas publicaciones, entre otras, nos permiten contar, en el presente, con un excepcional legado, fuente de información imprescindible para el conocimiento del litoral peninsular.

Desde sus primeras ediciones el Derrotero cuenta con una descripción pormenorizada y precisa del litoral y de cada uno de los referentes geográficos utilizados para la navegación. Esta información se ha ido acumulando y ampliando con vistas de la costa, ilustraciones de los faros, nuevas referencias aparecidas en el transcurso de los años, como puertos y otras infraestructuras, modernas edificaciones, etc. Así, paulatinamente, han ido apareciendo nuevos tomos a partir del único volumen de las primeras ediciones. Actualmente, el Derrotero publica los siguientes números:

- Derrotero núm. 1: Costa Norte de España, desde el río Bidasoa hasta la ría de Ribadeo, 2019.

Derrotero núm. 2: Costa Norte y Noroeste de España, desde la ría de Ribadeo hasta el cabo Finisterre, 2018.

Derrotero núm. 3: Costa Noroeste de España desde el cabo Finisterre hasta el río Miño, 2018.

- Derrotero núm. 4: Costa de Portugal e Islas Azores, que comprende desde el rio Miño hasta el rio Guadiana y las Islas Azores, 2019.

- $\quad$ Derrotero núm. 5: Costa Sudoeste y Sur de España que comprende desde el Río Guadiana hasta el Cabo Sacratif con las Costas Norte y Sur del Estrecho de Gibraltar, 2019.

Derrotero núm. 6: Costas sur y sudeste de España y costa norte de África, que comprende desde el cabo Sacratif hasta el cabo de La Nao, la costa norte de Marruecos y la costa de Argelia hasta el cabo Kramis, 2019.

Derrotero núm. 7: Costa este de España desde el cabo de La Nao hasta la frontera con Francia, 2019.

Derrotero núm. 8: Islas Baleares y costa Norte de África que comprende las Islas Baleares y la costa Norte de Argelia desde el Cabo Kramis hasta la frontera de Túnez, 2018.

Derrotero núm. 9: Costa Noroeste de África que comprende la costa noroeste de África desde el Cabo Espartel hasta el cabo Verde, las islas Madeira, Selvagens y Cabo Verde, 2018

Derrotero núm.10: Islas Canarias que comprende las Islas Canarias, 2019.

Cada edición está precedida de un capítulo denominado Generalidades que contiene:

a) Un mapa clave o índice gráfico en el que figura la referencia de las cartas que reseña el derrotero (Figura 1).

b) Los datos geográficos del litoral descrito en el libro, con alusión a la extensión que comprende, las provincias que incluye y la relación de costas, acompañada de una breve descripción, así como el enunciado de los principales puertos y fondeaderos naturales.

c) Un extenso y detallado epígrafe dedicado al clima y el tiempo de la zona. Comienza con la explicación general de la circulación atmosférica y continua con el análisis de los factores, tanto astronómicos como geográficos que confluyen en el clima. En diferentes subepígrafes se va considerando cada uno de los elementos del clima. En primer lugar, la presión y el viento, seguido de las temperaturas, precipitaciones, nieblas, nubosidad e insolación anual. Particular consideración se presta al régimen general de vientos y brisas de mar y tierra, con precisas descripciones de los más característicos, como: el siroco o lebeche, mistral, cierzo, tramontana, levante, poniente, terral, solano, vendavales, virazones, turbonadas, etc. en el Mediterráneo. En este epígrafe se incluyen también mapas de situación sinóptica de los tipos tiempos más frecuentes, junto a cuadros estadísticos de las estaciones meteorológicas del litoral, que en el Mediterráneo son las de Málaga, Almería, Alicante, Valencia, Castellón, Barcelona y Tarragona.

d) En el apartado Oceanografía se describen los fondos marinos, la plataforma continental y los lugares por donde corre el veril de los 100 metros. Las corrientes se ilustran con mapas y las mareas se precisan con sus correspondientes tablas.

e) En el apartado de Navegación el Derrotero del Mediterráneo expone las recaladas en el Estrecho, los dispositivos de separación del tráfico marítimo y las estaciones de salvamento marítimo. También se ubican las zonas de exclusión 
militar o aquellas en las que se llevan a cabo diferentes artes de pesca, como las almadrabas y que puedan suponer un peligro para la navegación.

f) En las ediciones anteriores al segundo tercio de siglo XX se incluyen otras informaciones muy diversas, como: tablas de reducción de metros a brazas españolas y pies de Burgos, advertencias sobre señales, reglas de balizamiento e instrucciones diversas dirigidas a capitanes y patrones.

En el presente, el Derrotero se debe completar con otras publicaciones como el Libro de Faros, para reconocer las marcas fijas y flotantes en las entradas a los puertos, y con otras publicaciones periódicas del Instituto Hidrográfico de la Marina como los Avisos a Los Navegantes, ya que en ellos aparecen las correcciones que hay que efectuar, no solo en el Derrotero, sino también en las cartas y en las demás publicaciones náuticas.

El grueso de la publicación describe por zonas todo el ámbito geográfico que comprende el Derrotero. En nuestro caso, consideraremos los capítulos o epí- grafes correspondientes a la Costa Malagueña que se tratan en el Derrotero número 3 de las Costas del Mediterráneo que comprende costas $N$ y $S$ del Estrecho de Gibraltar y la Costa Oriental de España desde Punta Europa hasta la frontera con Francia, que comprende un único volumen en la edición de 1950 y dos en la de 1973 y 1998.

En cada zona o tramo del litoral se hace referencia al relieve costero, a las construcciones y a las actividades que se realizan en el mismo. De todos estos elementos se precisa la posición geográfica, las distancias existentes entre unos y otros, y los posibles rumbos a seguir. Pensemos que el reconocimiento de la costa era de suma importancia para las travesías de cabotaje o para la orientación en altamar, así pues, los accidentes costeros y otros topónimos que designaban elementos de naturaleza física o humana, que son visibles desde el mar, siempre han resultado de gran utilidad para el navegante. Se pueden diferenciar, entre otros, los siguientes elementos o puntos de referencia geográfica:

a) Entre los topónimos relacionados con el medio físico continental se pueden diferenciar los

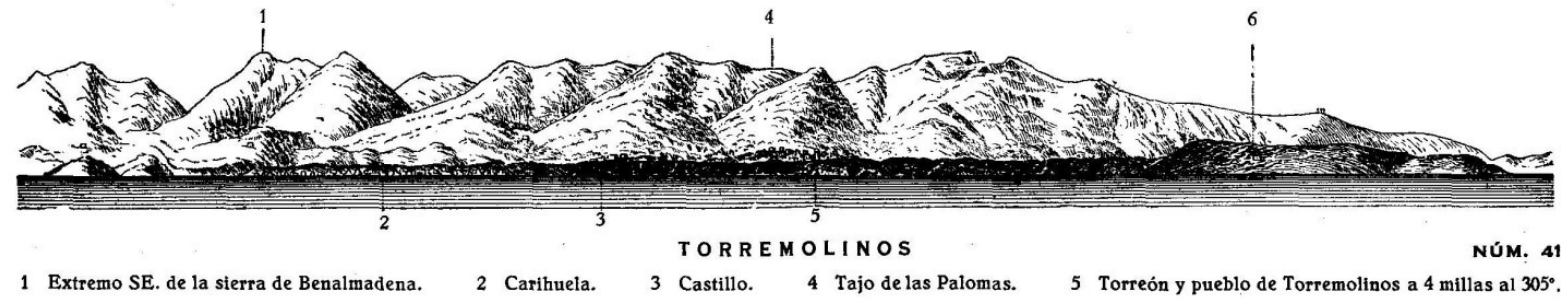

6 Loma de los Cardos.

Fuente: Derrotero de las Costas del Mediterráneo. Imprenta del Instituto Hidrográfico. Cádiz, 1950, p. 112

FIGURA 3

VISTAS DE LA COSTA DE TORREMOLINOS EN 1998

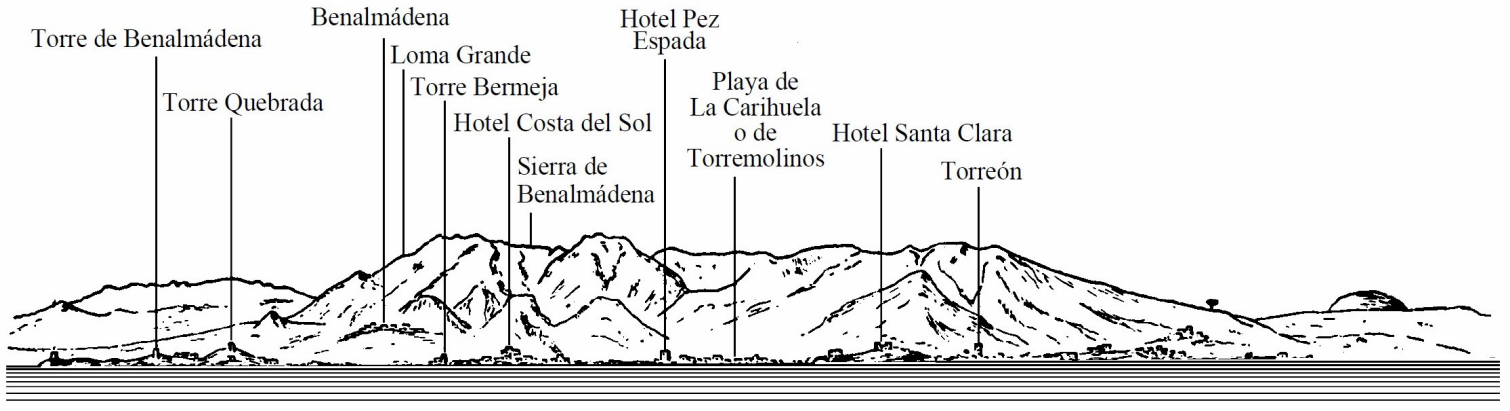

Torremolinos

Fuente: Derrotero de las Costas del Mediterráneo Núm. 3, Tomo I. Servicio de Publicaciones de la Armada. Cádiz, 1998, p. 130. 
principales relieves continentales: cordilleras, sierras, cerros, picos, peñones, saltos, etc.

b) Sin embargo, son los relieves litorales los que con mayor profusión se relatan: playas, dunas y arenales, cabos, puntas, acantilados, golfos, ensenadas, estuarios, calas y caletas, islotes, bancos, bajos, cabezos, arrecifes, restingas, piedras, roqueros, lajas, etc. Actualmente, muchos de ellos se confunden con los nuevos espigones, arrecifes, playas artificiales, diques o escolleras que dibujan una nueva y modificada línea de costa.

c) La hidrografía está presente en la sucesión de: canutos, lagunas litorales, marismas y de ríos, arroyos o ramblas que desembocan al mar.

d) La vegetación natural, aunque escasa, y los cultivos también aparecen indicados. Así nos muestran la existencia de pinares, diferentes cultivos y huertas próximos al litoral, etc.

e) Entre los elementos relacionados con la ocupación humana del litoral destacan las ciudades, villas, pueblos, poblaciones, arrabales, pobla- dos, caseríos, casas de labor, colonias pesqueras, casas y chozas de pescadores, casetas de carabineros. Y más recientes: las urbanizaciones, barrios, edificios, hoteles, casinos, complejos, chalés, campings, etc.

f) Destacan entre los edificios históricos: castillos, ruinas, iglesias, torres de iglesias, cementerios, ermitas y torres de defensa.

g) En cuanto a las infraestructuras se señalan: carreteras, puentes, acueductos, oleoductos, antenas o repetidores, paseos marítimos, emisarios submarinos o desagües sanitarios, cables submarinos, etc. Pero sobre todo están presentes las relacionadas con las actividades marítimas como: faros, radiofaros, balizas, marinas, boyas, sondas, luces, puertos, muelles, fondeaderos, cargaderos de mineral, etc.

h) Entre los elementos relacionados con las actividades económicas encontramos: puertos pesqueros y comerciales, marinas, fondeaderos, varaderos, salinas, almadrabas, fábricas de conserva, de azúcar y trapiches, depósitos, terminales de carga y descarga, etc.

FIGURA 4

VISTAS DE CABO SACRATIF EN 1950

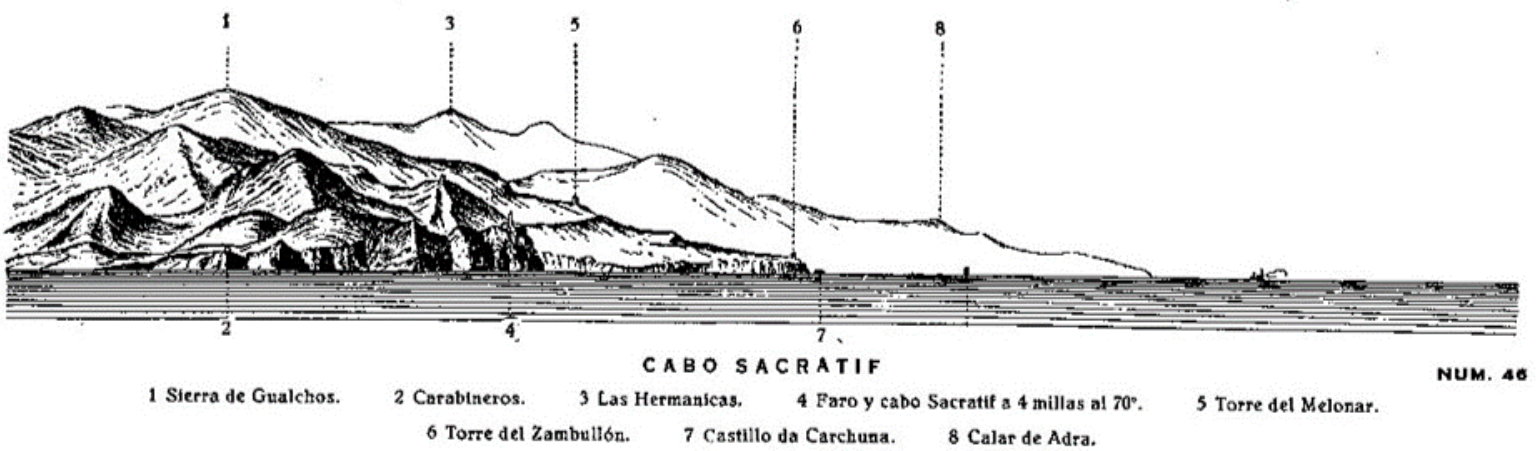

Fuente: Derrotero de las Costas del Mediterráneo. Imprenta del Instituto Hidrográfico. Cádiz, 1950, p. 126.

FIGURA 5

VISTAS DE CABO SACRATIF EN 1998

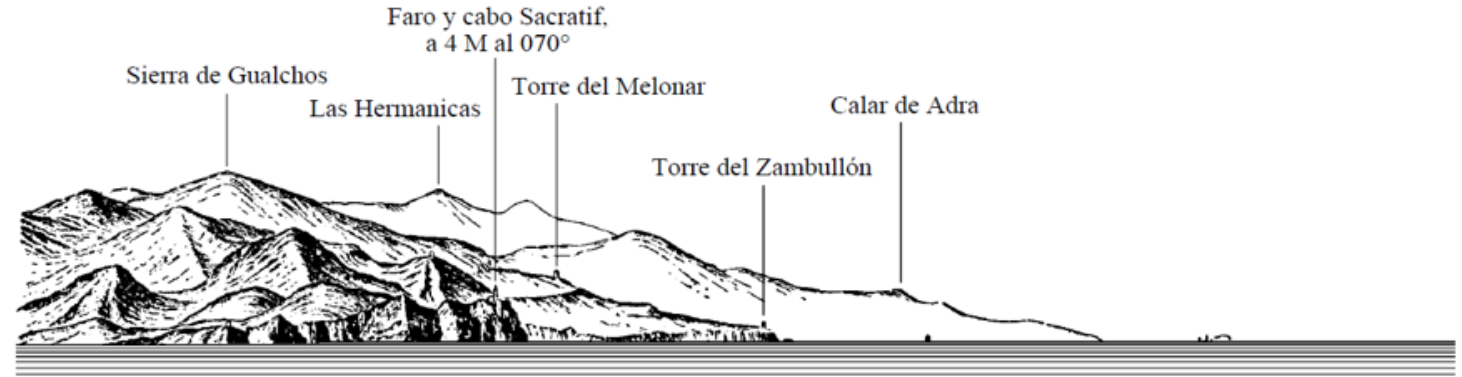

Vista de cabo Sacratif

Fuente: Derrotero de las Costas del Mediterráneo Núm. 3, Tomo I. Servicio de Publicaciones de la Armada. Cádiz, 1998, p. 152. 
En definitiva, están presentes en el Derrotero todas las unidades territoriales que diferencian las Directrices Regionales del Litoral de Andalucía, dentro de los cuales se producen los fenómenos más significativos y que funcionalmente caracterizan al dominio litoral, un territorio complejo en donde se identifican y delimitan: Sierras Litorales y Prelitorales, Acantilados, Dunas y Arenales Costeros, Ramblas, Lagunas, Playas, Estuarios y Marismas, Provincia Nerítica y Plataforma Continental (Decreto 118/1990).

La información gráfica se ha ido incrementando paulatinamente desde las primeras ediciones del Derrotero que, ya en sus ediciones del siglo XIX, cuenta con vistas a mano alzada de las costas y que permiten reconocer los diferentes accidentes geográficos. Posteriormente se fueron añadiendo láminas con los faros, islas e islotes más destacados y a mayor escala. Finalmente, en el presente, se acompañan de fotografías aéreas y planos de los puertos.

Si se comparan las vistas del mismo tramo de litoral en diferentes ediciones se evidencian las transformaciones ocurridas y la modificación de las referencias geográficas para la navegación, particularmente en la costa occidental (figuras 2 y 3 ) y en menor medida en la costa oriental (figuras 4 y 5 ) Es destacable también el hecho de que en esta publicación se haya mantenido la información de las primeras ediciones y las vistas a mano alzada, junto a las nuevas fuentes de información gráficas o que aportan los Sistemas de Información Geográfica. Incluso quedan vestigios de información dedicada a los grandes navíos de vela.

\section{LA COSTA MALAGUEÑA EN EL DERROTERO Y SU MO- DIFICACIÓN RECIENTE}

La costa de Málaga, denominado como Costa del Sol, se extiende desde la Punta de la Chullera en el límite con la Provincia de Cádiz al oeste, hasta los acantilados de Maro-Cerro Gordo en el límite con la provincia de Granada al este, a lo largo de aproximadamente $175 \mathrm{~km}$.

El perfil, poco recortado de este litoral, destaca por tener un telón de fondo formado por un conjunto de sierras litorales que sobrepasan los 1.000 metros de altitud sobre el nivel del mar y que pertenecen a la cordillera Penibética, en su mayoría al complejo Maláguide y Alpujárride. De oeste a este destacan: Sierra Bermeja, Sierra de las Nieves, Sierra Blanca, Sierra de Mijas, Montes de Málaga y Sierras Tejeda y Almijara. Ya en la descripción del relieve litoral andaluz que hacía Pedro Texeira en 1634 se presta una especial atención al malagueño, por ser este el más propenso a los desembarcos de corsarios, dado el elevado número de playas, calas, acantilados o desembocaduras que presenta, y entre las que destacan las bahías de Málaga y Estepona. Los estuarios y valles en esta franja, en cambio, son escasos y de reducida extensión, debido a una hidrografía que recibe exiguos y estacionales aportes, debido a la posición a sotavento de los Sistemas Béticos.

La división de la Costa Malagueña está comprendida en el Derrotero en los capítulos correspondientes de la Costa sur de España, de Gibraltar a Cabo de Gata, que a su vez se subdividen en diferentes epígrafes que diferencian tramos de costa no homogéneos y más reducidos conforme la edición del Derrotero es más reciente. Así el de 1950 solo diferencia dos zonas: la primera entre Punta Europa y Málaga y la segunda entre Málaga y cabo Sacratif. En cambio, el último considerado, el de 1998, distingue: entre la costa de Punta Europa a Estepona, entre Estepona y Marbella, de Marbella a Punta de Calaburras, de Punta de Calaburras a Málaga, y de Málaga a Punta de Jesús, ya en la costa de Granada. Es decir, los contenidos del Derrotero se han ido segmentando al ir ganando extensión y, consecuentemente, al haber ganado en información.

En la modificación de las referencias geográficas de los libros de Derrotero podemos diferenciar tres etapas fundamentales: hasta 1950, desde 1950 a 1975 y desde 1975 hasta finales del siglo XX. Para ello contamos con diferentes ediciones del Derrotero, justo en tres fechas clave: la de 1950, la de 1973 y la de 1998. Estas etapas son coincidentes con las que señalan García y Ocaña (1982) o Galacho (2000) en la evolución histórica del turismo en la Costa del Sol.

\section{Las referencias del litoral malagueño antes de 1950}

El Derrotero de 1950 nos muestra una línea de costa muy diferente a la actual: es la de un espacio poco evolucionado en el que lo natural y lo humano mantenían una relación equilibrada o sostenible. Así, en la sucesión de playas, cabos, ensenadas, deltas o acantilados encontramos una alternancia perfectamente diferenciada de torres de vigía, faros, pueblos, pequeños puertos pesqueros, colonias agrícolas, trapiches o fábricas de azúcar, cuarteles de carabineros, etc. Se puede afirmar que las fortificaciones y las torres almenaras, con las que se había erizado toda el litoral sur para advertir de los desembarcos de piratas y corsarios, fueron durante varios siglos las principales referencias geográficas o hitos verticales que guiaron la navegación costera, tanto por su emplazamiento como por el hecho de que se distanciaban entre si teniendo en cuenta el alcance de su visibilidad con respecto a la mayor longitud de espacio divisado y la posibilidad de avistar la torre anterior y posterior (Gil, 2000). En el presente han perdido casi todas ellas dicha función, ocultas o empequeñecidas por las torres de edificios situadas en primera línea de costa.

Sin embargo, en estas fechas ya se acusaban importantes modificaciones paisajísticas en la Costa Ma- 
lagueña, las cuales no cita el Derrotero y es preciso completar con fuentes documentales o bibliográficas, como las inducidas por la fracasada actividad siderúrgica del siglo XIX (García, 2007), que provocó la desforestación de grandes espacios en los montes y sierras de Málaga, los cuales proveían de carbón vegetal a las industrias y de madera a la construcción naval. Los desmontes realizados para viñedos de pasas o uvas de mesa y otros cultivos acentuaron el aprovechamiento de los recursos naturales, que finalmente se trasladaron a los espacios litorales mediante la intensificación de los regadíos costeros, en un intento de recuperar la actividad vinícola gravemente afectada por la filoxera de finales del siglo XIX (Galacho y Luque, 2000).

Los enclaves turísticos eran casi inexistentes. Puntualmente se localizan villas de recreo o balnearios de las clases sociales más pudientes y algunas residencias de alemanes e ingleses emparentadas con la nobleza o procedentes de Gibraltar. En La Carihuela o en la Playa del Bajoncillo en Torremolinos se encontraban este tipo de establecimientos (Lara, 1997), y ya en los años 30 aparecen los primeros hoteles de lujo en Málaga capital, como el Hotel Miramar, o en Torremolinos el Hotel Montemar. Pese a ello, no se encuentra referencia alguna a este tipo de nuevas construcciones en el Derrotero de 1950, pues eran escasas y no destacaban ostensiblemente en la línea del paisaje costero.

En dicha línea, en cambio, se observa una sucesión acompasada de tramos de litoral enmarcados por cabos o puntas sobre los que destaca un faro o torre vigía importante, y entre estos cabos o puntas se expone una precisa información de las ensenadas que comprenden. De oeste a este se va describiendo la sucesión de los elementos del relieve que destacan en el último plano: sierras litorales, picos, cerros, etc. En un plano intermedio se diferencian las villas y pueblos, con sus torres de iglesia, cementerios, caminos o carreteras, algunos calvarios, ríos, puentes, colonias agrícolas, castillos, ruinas o fábricas de azúcar. Ya en el primer plano, en el mismo litoral, se distinguen cultivos y huertas, pinares, colonias pesqueras, las casas y chozas de pescadores, torres vigías, casetas de carabineros, muelles, puertos pesqueros, fábricas de conserva, etc. Por último, en el dominio marítimo se presta especial atención a las posibilidades de recala$\mathrm{da}$, indicando los fondeaderos naturales y varaderos; pero tampoco se descuidan los elementos que puedan suponer un peligro para la navegación, como las almadrabas, los bajos, roqueros, lajas piedras, naufragios o bancos de arena. También se localizan minuciosamente los elementos que guían la navegación marítima además de los faros, como las balizas, boyas, sondas y luces.

Las referencias geográficas que emplea el Derrotero en 1950 permanecen prácticamente inalteradas si las comparamos con ediciones anteriores. Así, esta edición, nos muestra una combinación de elementos naturales y humanos que dibujan un territorio bien articulado y diferenciado, en el que el poblamiento, las actividades agrarias y pesqueras o marítimas coexisten, incluso junto a un incipiente turismo de minorías, apenas visible, pero que en la siguiente etapa se va a convertir en un fenómeno de masas que va a alterar definitivamente la línea litoral y las centenarias referencias que guiaban la navegación costera.

\section{Las referencias del litoral malagueño desde 1950 a 1975}

En la década de los años cincuenta se inicia la quiebra de la agricultura tradicional, que supone el trasvase de la población activa hacia la industria, la construcción y los servicios, resultando un importante éxodo migratorio hacia las ciudades o el extranjero (Gil y Gómez, 2001; Puyol, 1988; Terán, 1978). De forma paralela, en este periodo se consolida el modelo turístico de sol y playa en España, que tiene su principal paradigma en la Costa de Sol, la cual se convierte en un importante mercado receptivo a escala mundial. Así pues, la pérdida de peso demográfico que se estaba produciendo en las comarcas interiores y en la montaña media mediterránea no tuvo efecto en el litoral malagueño, más bien todo lo contrario. Además, esta etapa coincide también con un crecimiento regular y espectacular en los ingresos del turismo y en la afluencia de turistas extranjeros (Vallejo, 2002). Tanto es así que en 1971 España ya se sitúa como el segundo país en el ranking mundial de ingresos turísticos, por delante de Italia y solo superado por Estados Unidos (Fernández, 1991).

En Málaga, el turismo se va a convertir en el motor de su desarrollo económico, evitando la migración fuera de la provincia de sus habitantes, y generando inversiones privadas que rondaban los 10.000 millones de pesetas de la época (Galacho y Luque, 2000), de manera que los capitales españoles y extranjeros aprovechaban un nuevo mercado en el abanico de la oferta europea, sobre un territorio privilegiado, desde un punto de vista climático, y que conservaba intactos sus valores paisajísticos y medioambientales. Además, dichas inversiones, que obtenían enormes beneficios a corto plazo, no encontraban cortapisa ninguna por parte de la administración franquista que se inhibía de imponer una adecuada planificación territorial y económica.

De forma acelerada en la primera línea de costa, con frecuencia invadiendo el dominio marítimo-terrestre, irán levantándose grandes hoteles que sustituirán como referencia geográfica en los libros de Derrotero a faros, castillos y torres de vigía. Bien, por entorpecer la visión de estos desde el mar, o incluso por el derribo 
de dichas construcciones para levantar instalaciones residenciales $u$ hoteleras, como es el caso de la torre del Real de Zaragoza o del Castillo de Santa Clara. EI Derrotero menciona que entre la puntal del Real y el torreón del Lance de las Cañas existía "...la torre del real de Zaragoza, que actualmente ha desaparecido" (Derrotero, 1973: 123). En efecto fue demolida en 1954 para construir "una casa que lleva el nombre de las Dunas" (Gamir, 1960, p. 149).

Las nuevas edificaciones se van a constituir ahora en los nuevos hitos verticales que guíen la navegación en las aguas de este litoral, construcciones que parecen querer competir con los relieves penibéticos y que se dibujan en las vistas a mano alzada o perfiles de la costa que ilustran las ediciones del Derrotero de estos años (figura 2). En Torremolinos destacan el hotel Costa del Sol, el Hotel Santa Clara -construido sobre el castillo de Santa Clara- y el Hotel Pez Espada -inaugurado en 1959-. En Málaga capital el hotel Málaga-Palacio, finalizado en 1966, y que tapa la vista desde el mar de la Manquita o catedral de Málaga.

La construcción de complejos hoteleros no va a cesar en toda la etapa considerada, y a ella se suman nuevas actuaciones que buscan atraer un turismo de calidad promocionando las actividades náuticas mediante la construcción de puertos deportivos. También se concluyeron algunos puertos pesqueros, allí donde secularmente se ubicaban fondeaderos y varaderos utilizados por la pesca de bajura, como los de Estepona y Fuengirola. Así, en la década de los sesenta y setenta, estas actuaciones van a cambiar sensiblemente la línea costera de Málaga con terrenos ganados al mar mediante la construcción de nuevos diques y espigones que protegerán dichos puertos, pero alterando la dinámica litoral, lo que requeriría de nuevos diques para la protección o regeneración de las playas. Por ejemplo: en el puerto deportivo José Banús "al W. de Torre del Duque, se encuentra el espigón de la siesta, el espigón de Cañas Verdes y el espigón de protección de playas." (Derrotero, 1973, p. 122).

Además de los impactos paisajísticos y medioambientales, los puertos generan importantes efectos económicos relacionados con la especulación urbanística, pues allí donde se trazan los nuevos proyectos se genera una revalorización de los terrenos adyacentes. Asimismo, han actuado como elementos multiplicadores en las economías de los municipios donde se instalan (Junta de Andalucía, 1992 y 2004). En el Derrotero se va incorporando con gran detalle la aparición y características de las nuevas y de las ya existentes instalaciones portuarias. Así vemos como de forma consecutiva:

a) Al puerto pesquero de Estepona se le concedía la licencia deportiva a finales de los 50. b) El puerto pesquero Marina la Bajadilla, en Marbella, inició sus obras en 1955 y finalizaron en 1961. En 1967 se construyó un nuevo dique principal, de mayor longitud, que amplío la dársena para albergar embarcaciones de mayor calado.

c) La capital, Málaga, que ya contaba desde el siglo XIX con el Real Club Mediterráneo en el puerto de la ciudad, construye un nuevo puerto deportivo en 1965, entre la playa del Palo y el cerro del Candado, que se denominará Puerto deportivo de El Candado.

d) El puerto pesquero de Fuengirola inicio las obras de construcción en 1970, si bien, ya desde mediados del S. XIX, la bahía era un importante fondeadero y varada de la flota pesquera y de los barcos que fletaban la pasa que se producía en los campos de Mijas y Fuengirola.

e) Sería el Puerto deportivo Banús en Marbella, inaugurado en 1970, en medio de una gran expectación mundial, el mayor construido hasta el momento, con sus 915 atraques y calado suficiente para albergar los grandes yates de la jet set mundial.

f) En 1973 se ejecutó el proyecto denominado Cabo Pino. A partir de esa fecha la dualidad puerto-urbanización será ya una realidad indisolublemente ligada. Tanto es así, que las fechas de la concesión y las de aprobación del plan parcial de los terrenos coincidirán, prácticamente, en este y en sucesivos casos.

De la misma manera que las actividades náuticas, se va a vincular el deporte del golf a las promociones inmobiliarias. Pues, además de representar un nuevo tipo de oferta, suponía acoplarse a la creciente demanda de este turismo de calidad en toda Europa. Pero, además, porque los campos de golf aumentaban la calidad paisajística y los servicios complementarios de los nuevos complejos hoteleros y residenciales, o de los ya existentes. Sin embargo, en el Derrotero apenas encontramos referencias a los campos de golf por no tratarse estos de hitos verticales o espacios bien diferenciados desde el mar y que puedan servir de referencia para trazar derrotas. Así, solo se citan dos: El perteneciente al Real Club de Golf de Málaga, en las proximidades de la desembocadura del Guadalhorce y en el destacan "los edificios del Club de Golf entre arboleda, de color blanco con tejado rojo, y el hotel Las Mercedes" (Derrotero, 1973, p. 129). El segundo mencionado es el campo de golf Guadalmina que también alcanza la misma playa cerca de la punta de Baños. Hasta finales de siglo XX en Málaga se construyeron treinta campos de golf (Villar, 2011), casi todos ellos en los municipios litorales, y sobre todo en la 
costa del sol occidental. El primero fue el Real Club de Golf de Málaga en 1925, le sigue el de Guadalmina en 1959. En la década de los sesenta se hicieron cuatro más, en la de los setenta cinco, en los ochenta cinco, pero sería la década de los noventa cuando más se construyeron, hasta catorce.

Al finalizar la etapa considerada, se puede afirmar que el litoral malagueño ha sido profundamente transformado, y que se ha roto definitivamente esa línea de costa equilibrada y diferenciada en sus usos y actividades, perdida esa imagen de pequeños pueblos costeros, ahora ocultos y con buena parte de su caserío desaparecido por la implantación de numerosas torres verticales de hoteles ("Entre dicho hotel y el torreón del Lance de las Cañas, destaca el hotel Hilton, construcción blanca de unos catorce pisos con dos anexos de cuatro pisos a los lados." Derrotero, 1973, p. 122) y apartamentos en la primera línea de playa. Rota, también, por la extensión de manchas difusas de urbanizaciones, barriadas o bungalows que, alterando la lógica de una expansión urbana tradicional, lo hacen a saltos y de forma inconexa, comprometiendo cualquier intento posterior de ordenación urbana.

No obstante, todas estas estas modificaciones tuvieron un impacto desigual en el litoral, de manera que se puede afirmar que, al final de este periodo, aparece una clara división espacial y funcional del litoral malagueño en tres zonas bien diferenciadas: la costa del sol occidental, especializada en un turismo hotelero volcado sobre todo a la demanda extranjera; la costa del sol oriental, con un desarrollo más tardío, orientado al turismo interior y residencial, en donde se conserva buena parte de su actividad agraria; y la zona de la capital con funciones administrativas, comerciales y residenciales no turísticas (García y Ocaña, 1982).

\section{Las referencias del litoral malagueño desde 1975 a 1998}

El comienzo de esta etapa viene marcado por una crisis que afecta, tanto a la demanda como a la oferta turística, por una espiral inflacionista ocasionada por el alza de los costes energéticos a escala mundial. Sin embargo, tras un retraimiento coyuntural, las ventajas competitivas de la costa del Sol se fueron manteniendo gracias a la inversión en infraestructuras, la renovación de la oferta de alojamientos y la ocupación de los espacios vacíos y de mayor calidad medioambiental que restaban. Se consuma definitivamente el modelo turístico de sol y playa, con un crecimiento espectacular de las cifras absolutas, tanto de visitantes como de ingresos, que ahora van a tener una componente cíclica, conforme a las coyunturas económicas internacionales y la aparición de nuevos destinos turísticos.

También se sostuvo la intensificación del turismo residencial y de segunda residencia, con nuevos mo- delos de explotación del negocio turístico, como son los campos de golf y sus respectivas urbanizaciones residenciales, la construcción de parques temáticos y amplios resorts hoteleros. Así tras cincuenta años la franja litoral de Málaga se presenta profundamente marcada por la huella de las actividades turísticas y los intensos ritmos de urbanización, de forma que se evidencia una importante merma de los espacios naturales o de las actividades tradicionales como la agricultura (Galacho y Luque 2000; Almeida, 2002). Espacialmente se detecta una saturación urbanística del litoral en una doble dimensión: en la línea horizontal de costa siguiendo la $\mathrm{N}-340$, en un continuo residencial y de otros usos turísticos; y en una dimensión vertical, que va completando los espacios existentes entre el eje de la N-340 y la Autovía de la Costa del Sol A-7, o los tramos de la Autopista AP-7, alcanzando los relieves del traspaís Bético, en cotas que superan hasta los 400 metros (García, 2000).

El continuo urbano en la mayor parte del litoral no solo ha hecho desaparecer los ya escasos espacios naturales o los usos agrarios que restaban, sino que tampoco permite diferenciar ya donde comienzan o terminan las villas y pueblos, o donde se ubica su casco histórico, oculto por barreras de edificaciones de considerable altura en primera línea de playa. Los pueblos apiñados, emplazados en las laderas y piedemontes béticos, que se diferenciaban nítidamente desde el mar por tratarse de blancos caseríos con calles en cuesta y con iglesias que dominan sus lugares, apenas pueden distinguirse ya en un tejido donde se entremezclan complejos residenciales periféricos o urbanizaciones turísticas suburbanas, como en Mijas. Pero, no solo se han roto esos paisajes rurales de pueblos blancos, sino la estructura de un poblamiento que se había acrisolado durante siglos, desestructurando el territorio y los usos del suelo que constituían la base de unas comarcas litorales singulares del sudeste español. Entre otros impactos, también se refleja en el Derrotero el producido por el empleo de materiales alóctonos de diferentes tonalidades, y que paradójicamente pueden actuar como referencias náuticas. Así en la villa de Fuengirola el Derrotero de 1973 señala que "en el comienzo del pueblo existes varios hoteles altos de tejados, verde, rojo, ocre, etc.," (Derrotero, 1973, p. 125).

Las construcciones de tipo residencial, con tipologías indiferenciadas y que no respetan ni los volúmenes ni las tradiciones constructivas, estéticas o funcionales, ni tampoco se adaptan a los paisajes en los que se insertan, también tienen alguna reseña en el Derrotero. Por ejemplo: hacia el NNE de la Torre del Arroyo Vaquero "se encuentra el complejo Costa Natura, a partir de la misma playa siendo muy destacables sus construcciones en forma piramidal" (Derrotero, 1998, p. 113). Así, las nuevas edificaciones responden tanto 
a la falta de planificación urbanística como a la celeridad de un crecimiento demográfica que, en la costa del sol oriental, ha visto cuadriplicarse su población entre 1960 y 1998; o en la Axarquía, en donde casi se ha duplicado en el mismo periodo (López, Miranda, Posada, España y Moreno, 2000). Similar evolución ha experimentado la oferta de las plazas hoteleras, las cuales, al final del periodo considerado, también se duplicaron hasta alcanzar el 5,9 del total nacional (Vallejo, 2002).

La modificación en la línea de costa continúo acentuándose con la ampliación o la construcción de nuevos puertos deportivos, en algunos casos con terrenos modificados o ganados al mar. Así, acerca de la Punta de la Doncella o de las Peñas se dice: "Esta punta está situada a $700 \mathrm{~m}$ al 0690 de la anterior, y que, como ésta, es baja, roqueña, limpia y también modificada por los rellenos efectuados en el puerto de Estepona," (Derrotero, 1998, p. 114). Dichos puertos son:

a) El puerto pesquero y deportivo de la Caleta de Vélez, iniciado a partir del pequeño espigón hecho entre 1935 y 1937, y que no sería ampliado hasta finales de los años setenta. El recinto portuario quedó terminado en 1978.

b) El puerto deportivo La Duquesa en Manilva, finalizado en 1980.

c) El puerto deportivo Club Marítimo de Marbella fue diseñado con muelles y locales comerciales. Quedo terminado también en el año 1980.

d) Las obras del Puerto deportivo de Benalmádena comenzaron en noviembre de 1972 y, tras diversas fases de construcción, concluyeron con la inauguración el día 9 de octubre de 1982. Sobre unos $40.000 \mathrm{~m}^{2}$ de terrenos ganados al mar se extiende una importante zona comercial y residencial. Los muelles y pantalanes ocupan otros $64.000 \mathrm{~m}^{2}$ y permiten el amarre de más de 1.000 embarcaciones.

Vinculada a la actividad portuaria se encuentra también la actividad industrial, que también resulta muy visible desde el mar. El Derrotero de 1950 ya citaba algunos cargaderos de mineral, las chimeneas de diferentes trapiches o fábricas de azúcar, además de industrias en la ensenada de Málaga, como los Altos Hornos de Andalucía. El de 1973 menciona la fábrica de los Guindos en la Playa de San Andrés y el de 1998 los depósitos de gas de REPSOL y la terminal de amoniaco de S.A. Cros.

Al final de periodo considerado, en la línea litoral se ha producido, si cabe, una mayor densificación del tejido urbano, muy superior a la de la etapa anterior, como también muestran las ediciones del Mapa Topográfico Nacional (Figuras 6 y 7) o la ortofotografía.
Las consecuencias medioambientales también son graves, como la contaminación por vertidos urbanos al litoral, que en el caso de Málaga supera a todas las provincias andaluzas, como ponen de relieve de forma periódica los Informes de Medio Ambiente de la Junta de Andalucía (1987-2018). Aunque también se cita de forma explícita en el Derrotero, al señalarse el peligro que suponen los desagües sanitarios que vierten al mar: "Advertencia.-Debido a la existencia de numerosas instalaciones de desagües sanitarios submarinos, procedentes de las zonas urbanas existentes en el trozo de costa comprendido entre Estepona y Málaga, los navegantes que fondeen en sus proximidades, deberán tener en cuenta su existencia..." (Derrotero, 1998, p. 117).

Ahora casi todos los sistemas naturales han sido ocupados de forma indiscriminada, de manera que apenas quedan preservados algunos retazos en el Paraje Natural Acantilados de Maro-Cerro Gordo, en el Paraje Natural de la Desembocadura del Guadalhorce, ambos desde 1989, y en el más reciente, desde 2003, Monumento Natural Dunas de Artola o Cabopino, de apenas 20 ha.

Esta línea urbana indiferenciada, y que se proyecta de forma asimétrica en la Costa Malagueña, ha hecho desaparecer casi todos los referentes náuticos de épocas anteriores:

a) Torres de vigía, ahora ocultas entre bloques de edificios. Como la torre de Saladavieja que "se encuentra totalmente oculta por las construcciones de apartamentos que la rodean, siendo parcialmente visible al estar N-S con la misma" (Derrotero, 1998, p. 114).

b) Algunos faros, como el de Marbella, engullido por los edificios colindantes, más elevados, y alcanzando a iluminar sus áticos más que a los navegantes.

c) Edificios elevados que, por el contrario, hacen la función de faros por la luminaria de sus azoteas. Por ejemplo, el hotel Pez Espada de Torremolinos que actúa como faro "por su mayor altura y gran iluminación de luz roja en su parte más alta." (Derrotero, 1998, p. 129).

d) Boyas y espeques de señalización que no son visibles de noche por la elevada contaminación lumínica. Así se ha dado el caso de no diferenciarse, en ocasiones, la luz verde de estribor que guía la entrada en la bocana de los puertos por la contaminación lumínica que producen otras luces, como la verde de las farmacias, con posibles fatales consecuencias si no fuese por la ayuda de los sistemas de navegación por satélite. 
FIGURA 6

COSTA DE FUENGIROLA EN 1956

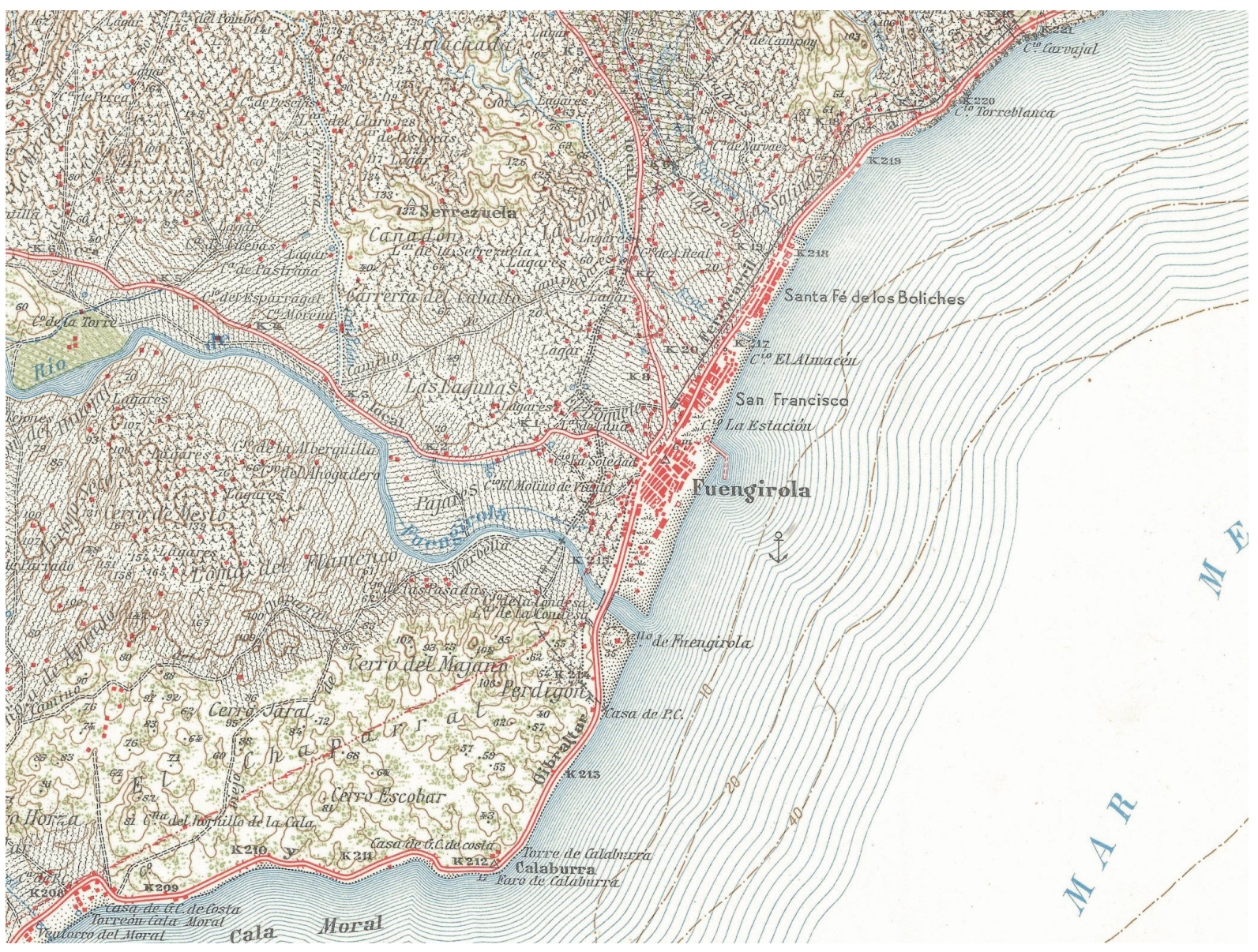

Fuente: MTN 1:50.000. Hoja 1066. Coín. Edición 1956.

Con todo se mantienen como referencias los relieves más elevados, si bien, sus piedemontes se han visto alterados paisajísticamente por la construcción de complejos residenciales unifamiliares de poca altura y baja densidad en Mijas, Benahavís, Marbella, Ojén y en bastantes municipios de la Axarquía.

En cambio, también se aprecia una mejor cartografía del litoral, con información más detallada de roqueros, piedras, lajas o arrecifes. Desde luego estas precisiones benefician a una ya creciente e importante flota de embarcaciones recreativas propia o que visita el litoral malagueño valiéndose de sus numerosos amarres. También se mantienen, en la última edición del siglo XX del Derrotero, los topónimos de ediciones anteriores, incluso las diferentes denominaciones de un mismo topónimo, por lo que no existe merma o pérdida de información geográfica. Cosa muy diferente a lo que ha sucedido, por ejemplo, en las diferentes ediciones del Mapa Topográfico Nacional en donde la toponimia ha experimentado modificaciones de diferente signo (Vázquez, 1982).
Al finalizar la etapa considerada se puede afirmar, con las vistas del Derrotero en la mano, que han quedado consagrados los ámbitos litorales de Málaga que diferenciara Marchena (1988): Por un lado, la aglomeración vertical y horizontal de TorremolinosBenalmádena-Fuengirola; otro ámbito, caracterizado por una intensa urbanización, entre Mijas-Marbella y Estepona en la costa occidental, y entre Rincón de la Victoria-Torre del Mar y Torrox en la costa oriental; y, por último, la existencia de dos sectores periféricos con una urbanización menos intensa y más difusa, uno en la costa occidental, entre Estepona-CasaresManilva y otro en la oriental, desde Nerja al límite de la provincia.

\section{CONCLUSIONES}

La Costa Malagueña, en el corto periodo de tiempo que comprende la segunda mitad del siglo $X X$, se ha convertido en uno de los espacios más modificados y dinámicos del Mediterráneo como consecuencia de las transformaciones territoriales, sociales y económi- 
FIGURA 7

COSTA DE FUENGIROLA EN 2004

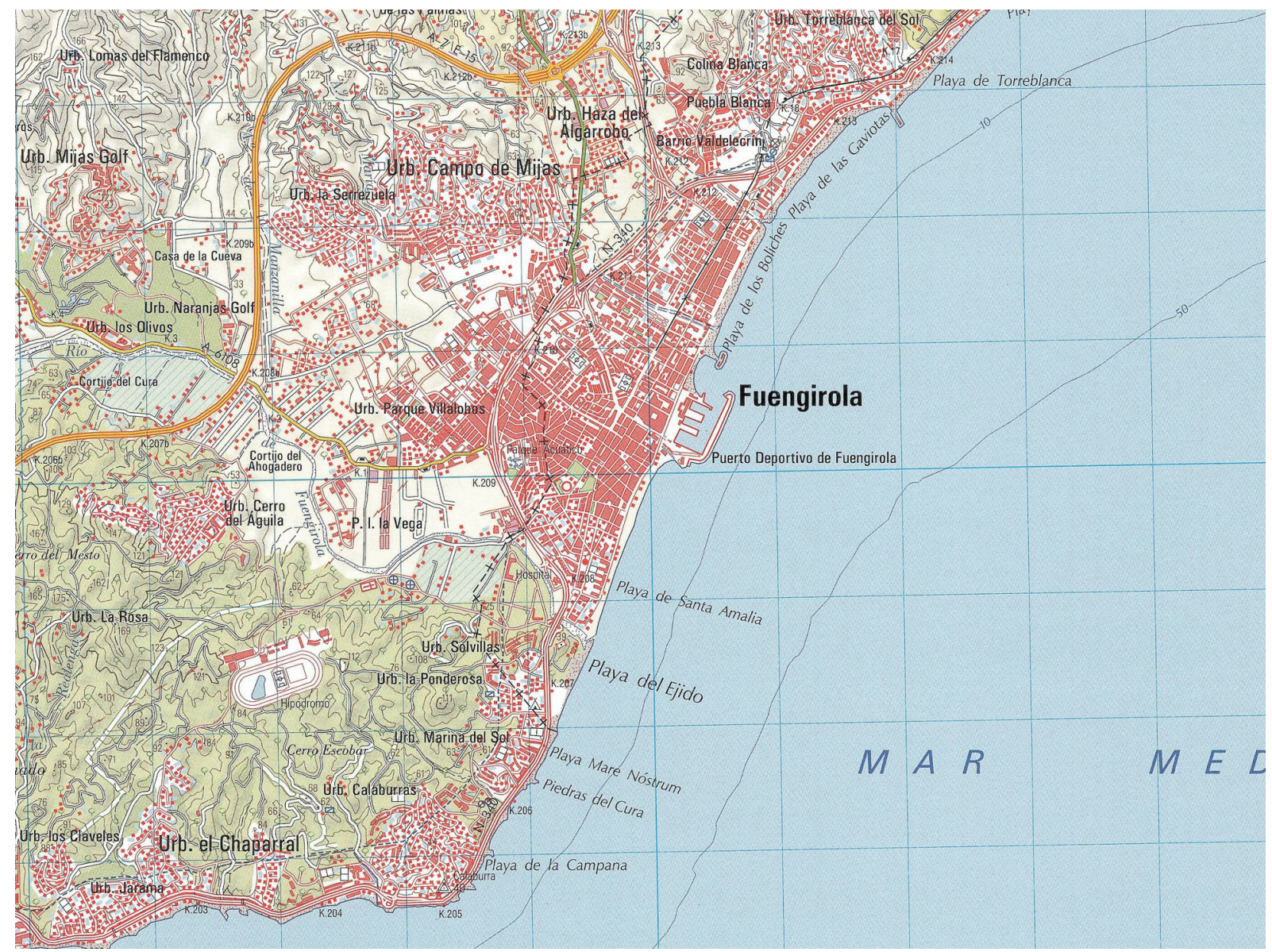

Fuente: MTN 1:50.000. Hoja 1066. Fuengirola. Edición 2004.

cas que ha inducido la actividad turística. Testigo excepcional de estas trasformaciones son los libros de Derrotero, sobre todo, de aquellas transformaciones cuyo impacto más visible se hace en la franja litoral. Una franja que hace de nexo entre el estrecho de Gibraltar y el Levante, y que ha devenido en uno de los ejes con mayor poder de articulación territorial de Andalucía Oriental y del litoral mediterráneo español. El motor de estas transformaciones ha sido el turismo que, a su vez, ha impulsado otras actividades como la pesca, la agricultura intensiva, la industria, las comunicaciones, el poblamiento, la actividad portuaria y comercial. Sobrepasada la inicial oferta de turismo de sol y playa, ha ido adquiriendo mayor relevancia el turismo residencial, el deportivo, el náutico, el de congresos y exposiciones o el de parques temáticos, actividades que han impulsado las infraestructuras y comunicaciones, un poblamiento casi continuo de la fachada litoral y una renovada actividad portuaria y comercial.

Debemos convenir, que los efectos espaciales y visuales que se han causado en el litoral malagueño han sido extraordinarios, -como recogen las cada vez más recientes y voluminosas ediciones del Derrotero-. Pero, no lo han sido menos las trasformaciones socioeconómicas y las producidas en la propia estructuración funcional de los espacios. Así se ha ocasionado un deslizamiento gravitacional del peso demográfico de la provincia prácticamente hasta la cota del nivel del mar, pero además se ha atraído a una buena parte de la población andaluza, particularmente de cordobeses o jienenses, que han establecido allí su segunda residencia, incluso de numerosos extranjeros que se han establecido de forma definitiva tras su jubilación. Esta atracción de personas y rentas ha actuado como generadora de empleo, y con ello de un sinfín de servicios orientados a la actividad turística, a falta de otras actividades como la industria. Por otro, lado los intentos de intentar una ordenación espacial y funcional de las actividades turísticas mediante políticas de planeamiento u ordenación del territorio han fracasado en buena medida, evidenciada su ausencia, su retraso en aparecer o la imposibilidad de llevarlas a cabo en unos marcos normativos de carácter municipal desiguales. 
El paisaje costero que dibuja el Derrotero, visto desde el mar Mediterráneo, es la resultante, después de cincuenta años, de un territorio profundamente modificado, de forma casi irrevocable y que muestra: una abigarrada línea de diferente grosor, rota desde un punto de vista funcional y físico en promociones de un caprichoso pintoresquismo, que desgarran visualmente los paisajes en donde se ubican; una serie de infraestructuras y servicios que difícilmente pueden articular un territorio tan fragmentado; $y$, una miscelánea de espacios no construidos, vacíos, yermos o desforestados, muchos de ellos descarnados por canteras. De manera que casi no se puede hablar de espacios naturales, aunque algunos estén ocupados con masas repobladas, y otros por un abigarrado mosaico de cultivos que se presentan más continuo en la parte oriental. Parece que solo los picos de los relieves penibéticos más elevados permanecen como referentes intactos para realizar los cálculos oportunos de los navegantes.

Igualmente, los libros de Derrotero muestran que las transformaciones paisajísticas que han tenido lugar en el litoral malagueño se han producido de un modo desigual. Coincidiendo esta apreciación con los autores ya señalados, y que diferenciaban: un litoral profundamente modificado en la costa del sol occidental y otro menos modificado en la costa del sol oriental. Así se demuestra la concordancia entre derrotero y buena parte de los estudios geográficos. Pues el Derrotero, desde el punto de vista de la navegación, vendría a corroborar, no solo la división espacial del litoral malagueño que sostiene la bibliógrafa de carácter geográfico, sino también la división cronológica que sostiene aquella en las etapas que ya se han expresado.

Para concluir, debemos advertir que no se puede obviar que, de la misma manera que se han producido profundas alteraciones paisajísticas, urbanas, demográficas, económicas, e incluso culturales, en el litoral malagueño, también se han producido profundas alteraciones en la geografía del mar, no solo por la modificación de la morfología litoral o de los fondos marinos, sino también en la misma navegación, que encuentra nuevos peligros y ve modificadas las referencias y coordenadas a la hora de establecer derrotas, enfilaciones o distancias, tanto en la navegación comercial, recreativa como pesquera.

Por consiguiente, y teniendo en cuenta todo lo expresado anteriormente, se podría afirmar que las diferentes ediciones de los libros de Derrotero no solo son un testigo documental y visual extraordinario de las alteraciones producidas en los paisajes costeros, o de los cambios producidos en la misma morfología del litoral, son también la prueba de que se han modificado las referencias geográficas de la Costa Malagueña.
En definitiva, se podría considerar que el estudio de los Derroteros constituye una herramienta más para el análisis de los espacios costeros, junto a otras fuentes documentales, estadísticas o cartográficas como los mapas topográficos o la imagen satelital. Además, teniendo en cuenta la periodicidad, extensión y uniformidad de dichas publicaciones, se podría considerar que su utilidad se podría hacer también extensible al estudio de todos los espacios costeros peninsulares e insulares.

\section{REFERENCIAS BIBLIOGRÁFICAS}

Asociación de Geógrafos Españoles (AGE). (2014). Alegaciones AGE al proyecto de R.D sobre los currículos de ESO y del Bachillerato. Análisis y alegaciones de la AGE al Proyecto de Real Decreto sobre los currículos de Educación Secundaria Obligatoria y del Bachillerato. Recuperado de http://www.agegeografia.es/site/wp-content/uploads/2015/02/ Alega_AGE_RD_Educacion_DEF.pdf

Almeida, F. N. (2002). La costa del Sol oriental un conflicto territorial entre el turismo, la agricultura y la urbanización metropolitana. En P. Pumares, M. A. Asensio y F. Fernández (Ed.), Turismo y transformaciones urbanas en el siglo XXI (pp. 137-147). Almería, España, Universidad de Almería.

Almeida, F. N., Cortés, R. y Balbuena, A. (2019). Tourism-phobia in historic centres: the case of Malaga. Boletín de la Asociación de Geógrafos Españoles, 83, 1-32. doi: https://doi.org/10.21138/ bage. 2823

Álvarez, J., y Lázaro, M. L. (2019). Las infraestructuras de datos espaciales: un reto y una oportunidad en la docencia de la Geografía. Boletín de la Asociación de Geógrafos Españoles, 82, 1-32. doi: http://dx.doi.org/10.21138/bage. 2787

Castells, M. (1989). Nuevas tecnologías y desarrollo regional. Economía y Sociedad, 2, 11-22.

De Miguel, R. (2018). Geografía y tiempo contemporáneo: educación geográfica y enseñanza de las ciencias sociales para el mundo global. REIDICS: Revista de Investigación en Didáctica de las Ciencias Sociales, 2, 36-54. doi: https://doi. org/10.17398/2531-0968.02.36

Decreto 118/1990, de 17 de abril, por el que se aprueban las Directrices Regionales del Litoral de Andalucía. (BOJA núm. 40, de 18 de mayo). Recuperado de https://www.juntadeandalucia.es/ boja/1990/40/15 
Dollfus, O. (1975). El espacio geográfico. Barcelona, España: Oikos-tau.

Durand, P. (2005). Milieux littoraux: Nouvelles perspectives d'étude. France: Comité National Français de Géographie, Commission Geographie de la Mer.

Fernández, L. (1991). Historia general del turismo de masas. Madrid, España: Alianza Editorial.

Ferre, E. y Ruiz, J. D. (1986). Algunos aspectos del impacto del turismo en la Costa del Sol occidental: El caso de Marbella. Baética, 9, 57-74.

Galacho, F. B. (1996). Urbanismo y turismo en la Costa del Sol. Málaga, España: Universidad de Málaga.

Galacho, F. B. y Luque, A. M. (2000). La dinámica del paisaje de la Costa del Sol desde la aparición del turismo. Baética, 22, 25-58.

Gallegos, A. (2018). Caracterización y análisis de los riesgos naturales en el planeamiento urbanístico del litoral mediterráneo español. Málaga, España: Ed. Universidad de Málaga.

Gamir, A. (1960). Las fortificaciones costeras del reino de Granada al occidente de la ciudad de Málaga hasta el Campo de Gibraltar. Miscelánea de Estudio Árabes y Hebraicos, 9, 135-156.

García, E. y Ocaña, C. (1982): “La organización espacial de la Costa Mediterránea Andaluza. Baetica, 5, 15-57.

García, E. (2000). Los espacios turísticos del litoral andaluz. Cuadernos Geográficos, 30, 43-76. Recuperado de https://revistaseug.ugr.es/index.php/ cuadgeo/article/view/1955

García, C. (2007). La crisis de la siderurgia Malagueña. Revista de estudios regionales, 79, 291-313. Recuperado de http://www.revistaestudiosregionales. com/documentos/articulos/pdf928.pdf

Gil, A y Gómez, J. (2001). Geografía de España. Barcelona, España: Ariel.

Gil, J. (2000). La nueva frontera y la defensa de la costa. En M. Barrios y R. G. Peinado, (Ed.), Historia del Reino de Granada. Tomo II (543-581). Granada, España: Universidad de Granada.

González, F. y Blay, J. (2019). La atracción migratoria de las ciudades turísticas y la transformación del sistema urbano litoral mediterráneo español. Un análisis a escala local del período 1991 a 2011. Revista de estudios regionales, 114, 171-196. Recuperado de http://www.revistaestudiosregionales.com/documentos/articulos/pdf-articulo-2566.pdf
Górgolas, P. (2020). El urbanismo en el litoral andaluz tras la última burbuja inmobiliaria: cambio de ciclo o reincidencia. Valencia, España: Tirant lo Blanch.

Instituto de Estadística y Cartografía de Andalucía (IECA). (2016). La Costa del Sol en los albores de su desarrollo turístico: el vuelo de ESBOGA de 1963-64. Sevilla, España: Instituto de Estadística y Cartografía de Andalucía. Recuperado de: http:// www.juntadeandalucia.es/institutodeestadisticaycartografia/blog/2016/05/costal-del-sol/.

Instituto Hidrográfico de la Marina (1950). Derrotero de las Costas del Mediterráneo desde el Cabo de trafalgar hasta la frontera con Francia, las Islas Baleares, la costa N. de Marruecos desde el cabo Espartel, y la costa de Argelia. Núm. 3. Cádiz, España: Imprenta del Instituto Hidrográfico.

Instituto Hidrográfico de la Marina (1973). Derrotero de las Costas del Mediterráneo que comprende Costas $N$ y $S$ del Estrecho de Gibraltar y la Costa Oriental de España desde Punta Europa hasta la frontera con Francia. Núm. 3, Tomo I. Cádiz, España: Imprenta del Instituto Hidrográfico.

Instituto Hidrográfico de la Marina (1998). Derrotero de las Costas del Mediterráneo que comprende Costas $N$ y S del Estrecho de Gibraltar y la Costa Oriental de España desde Punta Europa hasta la frontera con Francia. Núm. 3, Tomo I. Cádiz, España: Servicio de Publicaciones de la Armada. Talleres del Instituto Hidrográfico de la Marina.

Junta de Andalucía (1992). Puertos pesqueros y deportivos en Andalucía. Sevilla, España: Consejería de Obras Públicas y Transportes.

Junta de Andalucía (2004). Andalucía y sus puertos. 1983-2003. Sevilla, España, Consejería de Obras Públicas y Transportes, Empresa Pública de Puertos de Andalucía.

Junta de Andalucía (1987-2018). Informes de Medio Ambiente. Sevilla, España, Consejería de Agricultura, Ganadería, Pesca y Desarrollo Sostenible.

Lara, M.P. (1997). Balnearios en Torremolinos. Isla de Arriarán: revista cultural y científica, 10, 227-246.

López, E., Miranda, J., Posada, J. C., España, I. y Moreno, J. G. (2000). Articulación del espacio litoral. En G. Cano (Ed.), Conocer Andalucía: gran enciclopedia andaluza del siglo XXI. vol. 10 (178-219). Sevilla, España: Tartessos. 
Luque, R. M. (2011). El uso de la cartografía y la imagen digital como recurso didáctico en la enseñanza secundaria. Algunas precisiones en torno a Google Earth. Boletín de la Asociación de Geógrafos Españoles, 55, 183-210. Recuperado de https://www.age-geografia.es/ojs/index.php/ bage/article/viewFile/1318/1241

Marchena, M. (1987): Territorio y Turismo en Andalucía. Sevilla, España: Junta de Andalucía.

Marchena, M. (1988). El turismo en Andalucía. En G. Cano, (Ed.), Geografía de Andalucía. tomo VI (263-346). Sevilla, España: Tartessos.

Miossec, A. (1998). Géographie humaine des littoraux maritimes. France, CNED.

Natera, J.J y Batista, A.E. (2019). Dinámicas recientes de la población en municipios rurales de la Axarquía malagueña con elevada presencia de extranjeros (2003/2017). Cuadernos geográficos de la Universidad de Granada, 58 (3), 25-144. doi: http://dx.doi.org/10.30827/cuadgeo.v58i3.8634

Navarro, E., Romero, Y. y Romero, J. M. (2020). Destinos turísticos litorales en España: Crecimiento, reacción social y postcrecimiento. El caso de la Costa del Sol-Málaga. En G. X. Pons, A. Blanco, L. Troitiño y M. Blázquez (Ed.), Sostenibilidad turística: "overtourism vs undertourism" (pp. 43-56). Palma, España: Societat d'Història Natural de les Balears. Recuperado de https://dialnet.unirioja. es/servlet/libro?codigo $=776500$ \&orden $=0$ \&info $=$ open_link_libro

Nonn, H. (1987). Geografía de los litorales. Madrid, España: Akal.

Puyol, R. (1988). La población española. Madrid. España: Síntesis.

Río, J. L. (2017). Impacto del uso del suelo y la explotación de los recursos naturales en la dinámica sedimentaria litoral: estudio interdisciplinar de la evolución reciente en el municipio de Marbella (provincia de Málaga). (Tesis doctoral). Universidad Pablo de Olavide, Sevilla, España.

Riudavets, P. (1867). Derrotero de las costas de España y de Portugal: desde el Cabo Trafalgar hasta el puerto de la Coruña España. Madrid, España: Dirección de Hidrografía.

Simancas, M. (Ed.). (2016). La planificación y gestión territorial del turismo. Barcelona, España: Síntesis.

Suárez, J. L. (1999). Delimitación y definición del espacio litoral. En A. Viciana y A. Galán, (Ed.), Actas de las Jornadas sobre el litoral de Almería: caracterización, ordenación y gestión de un espacio geográfico (pp. 13-23). Almería, España: Instituto de Estudios Almerienses.

Teixeira, P. (2002). Descripción de España y de las costas y puertos de sus reinos (1634). F. Pereda, y F. Marías (Ed.). Hondarribia, España: Nerea.

Terán, M. de, Solé, L. y Vilá, J. (1978). Geografía General de España. Barcelona, España: Ariel.

Tofiñó, V. (1787). Derrotero de las costas de España en el Océano Atlántico, y de las Islas Azores ó Terceras, para inteligéncia y uso de las cartas esféricas. España: Imprenta de la viuda de Ibarra, Hijos y Compañía, ed.

Vallejo, R. (2002). Economía e historia del turismo español del siglo XX. Historia Contemporánea, 25, 203-232. Recuperado de https://ojs.ehu.eus/index.php/HC/article/download/5934/5614

Vázquez, F. (1982). La toponimia en el Mapa Topográfico Nacional. Boletín de la Real Sociedad Geográfica, 118, 99-104. Recuperado de https:// realsociedadgeografica.com/boletines/Tomo\%20 CXVIII\%20-\%201982.pdf

Villar, A. (2011). Territorio, turismo y paisaje: el proceso de urbanización en el litoral de Andalucía. El papel de los campos de golf. Recuperado de http://www.juntadeandalucia.es/turismoycomercio/publicaciones/143334969.pdf 